University of Wollongong

Research Online

Faculty of Engineering and Information

Faculty of Engineering and Information

Sciences - Papers: Part A

Sciences

$1-1-2014$

\title{
Feasibility study of low force robotic friction stir process and its effect on cavitation erosion and electrochemical corrosion for Ni Al bronze alloys
}

\author{
Azman Ahmad \\ University of Wollongong, aba451@uowmail.edu.au \\ Huijun Li \\ University of Wollongong, huijun@uow.edu.au \\ Zengxi Pan \\ University of Wollongong, zengxi@uow.edu.au \\ Dominic Cuiuri \\ University of Wollongong, dominic@uow.edu.au \\ Stephen van Duin \\ University of Wollongong, svanduin@uow.edu.au
}

See next page for additional authors

Follow this and additional works at: https://ro.uow.edu.au/eispapers

Part of the Engineering Commons, and the Science and Technology Studies Commons

Research Online is the open access institutional repository for the University of Wollongong. For further information contact the UOW Library: research-pubs@uow.edu.au 


\title{
Feasibility study of low force robotic friction stir process and its effect on cavitation erosion and electrochemical corrosion for Ni Al bronze alloys
}

\author{
Abstract \\ Robotic friction stir processing (FSP) has not been widely researched to date. This is perhaps due to the \\ limited force capabilities of industrial robots in comparison with dedicated commercial FSP equipment. \\ When operating a FSP machine, the force used to plunge the tools may range from 5000 to $8000 \mathrm{~N}$ which \\ is currently beyond the capability of most robots. However, the capacity of robotic manipulators is \\ increasing, so low force friction stir processing is becoming feasible. The ability of the robot arm to apply \\ a controlled force that is normal to a 3-dimensional surface without the need to reorient the workpiece \\ makes it a very useful tool for FSP of complex components. In this analysis, a robot arm with a capacity \\ of $2500 \mathrm{~N}$ is used to improve the surface properties of nickel aluminum bronze (NAB) using low force \\ FSP. Multiple passes were applied to the surface of the test sample for a more consistent spread of the \\ stir zone. The sample was then microhardness tested and demonstrated a 62 pct increase in surface \\ hardness. Cavitation erosion testing of the original and processed surfaces was also performed as per \\ ASTM G-32. The erosion rate of the processed NAB sample was 44 pct of the rate experienced by the \\ original cast NAB sample. Finally, the corrosion potentials of FSP NAB were measured at $45 \mathrm{mV}$ less \\ anodic than the unprocessed material, indicating that the processed material is more noble relative to the \\ cast NAB sample. \\ Disciplines \\ Engineering | Science and Technology Studies

\section{Publication Details} \\ Ahmad, A., Li, H., Pan, Z., Cuiuri, D., Van Duin, S., Larkin, N., Polden, J. \& Lane, N. (2014). Feasibility study of \\ low force robotic friction stir process and its effect on cavitation erosion and electrochemical corrosion \\ for Ni Al bronze alloys. Metallurgical and Materials Transactions B: Process Metallurgy and Materials \\ Processing Science, 45 (6), 2291-2298.
}

\section{Authors}

Azman Ahmad, Huijun Li, Zengxi Pan, Dominic Cuiuri, Stephen van Duin, Nathan Larkin, Joseph Polden, and Nathan Lane 


\title{
Feasibility Study of Low Force Robotic Friction Stir Process and its Effect On Cavitation Erosion and Electrochemical Corrosion for Ni Al Bronze Alloys
}

\author{
AZMAN AHMAD, HUIJUN LI, ZENGXI PAN, DOMINIC CUIURI, \\ STEPHEN VAN DUIN, NATHAN LARKIN, JOSEPH POLDEN, and NATHAN LANE
}

\begin{abstract}
Robotic friction stir processing (FSP) has not been widely researched to date. This is perhaps due to the limited force capabilities of industrial robots in comparison with dedicated commercial FSP equipment. When operating a FSP machine, the force used to plunge the tools may range from 5000 to $8000 \mathrm{~N}$ which is currently beyond the capability of most robots. However, the capacity of robotic manipulators is increasing, so low force friction stir processing is becoming feasible. The ability of the robot arm to apply a controlled force that is normal to a 3 -dimensional surface without the need to reorient the workpiece makes it a very useful tool for FSP of complex components. In this analysis, a robot arm with a capacity of $2500 \mathrm{~N}$ is used to improve the surface properties of nickel aluminum bronze (NAB) using low force FSP. Multiple passes were applied to the surface of the test sample for a more consistent spread of the stir zone. The sample was then microhardness tested and demonstrated a 62 pct increase in surface hardness. Cavitation erosion testing of the original and processed surfaces was also performed as per ASTM G-32. The erosion rate of the processed NAB sample was 44 pct of the rate experienced by the original cast NAB sample. Finally, the corrosion potentials of FSP NAB were measured at $45 \mathrm{mV}$ less anodic than the unprocessed material, indicating that the processed material is more noble relative to the cast NAB sample.
\end{abstract}

DOI: $10.1007 / \mathrm{s} 11663-014-0152-6$

(c) The Minerals, Metals \& Materials Society and ASM International 2014

\section{INTRODUCTION}

NiCKEL aluminum bronze (NAB) alloy is widely used in marine environments for critical items such as propellers, impellers, pumps, valves, and heat exchangers due to a combination of its mechanical properties and excellent erosion-corrosion resistance. NAB is more cathodic (more corrosion resistant) relative to steel, ${ }^{[1]}$ and this is the main reason why most of the marine engineering companies will favor NAB as their material for their marine components due to its capability to better withstand extreme sea conditions. Nevertheless, the material still suffers from the effects of corrosion and cavitation which results in annual costs of millions of dollars in repairs and replacement.

NAB alloys contain approximately 83 pct copper and 9 to 12 pct aluminum, with the remainder consisting of iron, nickel, and some impurities. The presence of $\mathrm{Ni}$ and $\mathrm{Fe}$ in the $\mathrm{Cu}-\mathrm{Al}$ alloys increases the terminal $\mathrm{FCC} \alpha$ phase area and suppresses the formation of $\Upsilon$-phase in the $\mathrm{Cu}-\mathrm{Al}$ alloys. Further, $\mathrm{Al}_{4} \mathrm{Cu}_{9}$ are damaging to the

AZMAN AHMAD and JOSEPH POLDEN, Ph.D. Students, HUIJUN LI, Associate Professor, ZENGXI PAN, DOMINIC CUIURI, and STEPHEN VAN DUIN, Senior Research Fellows, and NATHAN LARKIN and NATHAN LANE, Research Fellows, are with the Faculty of Engineering and Information Science, University of Wollongong, Wollongong, NSW, Australia. Contact e-mail: aba451@uow.edu.au

Manuscript submitted December 2, 2013 corrosion resistance of the alloys due to high aluminum content. ${ }^{[2]}$ Cast NAB consists of coarse Widmanstätten $\alpha$ phase, nickel-iron-aluminum $\mathrm{K}$ phases and island martensite $\beta$ phase, and the transformation phase. ${ }^{[3]}$ The poor casting properties of NAB can result in porosity, defects, and imperfections that degrade the mechanical and the corrosion properties of the final component.

In order to improve the erosion-corrosion resistance of $\mathrm{NAB}$, various metallic and organically based coatings have been tested. ${ }^{[4]}$ While these coatings reduce the corrosion effects, the mechanical properties of the material are not enhanced.

Friction stir processing has been successfully used to reconstruct the microstructure of heterogeneous metallic materials. The FSP technique has been shown to refine the coarse microstructure of cast NAB, eliminate porosities, and homogenise the microstructure thus increasing hardness, tensile properties, and fatigue strength. ${ }^{[5]}$ Oh-ishi et al. ${ }^{[6]}$ report that the main characteristic of the stir zone (SZ) of FSP NAB was inhomogeneous microstructures in various subregions, including Widmanstätten structure, equiaxed fine grain structure, or lamellar structure. Ni et $a l .{ }^{[7]}$ state that the inhomogeneous microstructure was parameter dependent in which the tensile and the hardness were increased significantly. ${ }^{[7]}$ A particular function of FSP is able to create localised modification and control of the microstructure in the surface region without altering the overall shape and dimensions of the components.

Having established that FSP can make significant improvements to the surface properties of cast NAB, 
attention must then be given to the engineering aspects of applying this process industrially.

According to Longhurst,${ }^{[8]}$ the plunge forces required for FSP/FSW vary from 5000 to 8000 N. These values are acceptable if using a dedicated FSW machine; however, these machines are typically restricted to flat surfaces. For marine components, which often feature contours and other complex geometry, these dedicated FSW machines are unsuitable. However, industrial robotic manipulators could be utilised in these situations to carry out FSP on non-planar surfaces. The high number of movable degrees of freedom of a manipulator, and its relatively large work volume, can allow it to maneuver a FSP tool along a contoured surface. One related drawback to this proposal is that robotic arms currently cannot supply the force specified in ${ }^{[8]}$ to carry out the process. The vibration generated from the friction stir process is also an area of concern since robot manipulators do not have the rigidity of dedicated FSP equipment.

Therefore, a study is needed to determine whether the friction stir process is still effective in improving the surface properties of NAB when applied with forces that are achievable using robotic manipulators that are currently available. This study will apply robotic FSP at $1750 \mathrm{~N}$, or approximately $25 \mathrm{pct}$ of the force used by conventional FSP machines in previous studies. The present research focus on

- Observing changes in the microstructure after the FSP process and determining the effects that these changes may have on mechanical properties of the surface.

- Measuring changes in hardness and grain size.

- Investigating effects of cavitation using the vibratory apparatus and an accelerated corrosion analysis using the Tafel polarization method.

\section{A. Microstructural Properties of $N A B$}

Cast NAB is categorized by its complex phases and phase realisations during cooling. Below $1303 \mathrm{~K}$ $\left(1030{ }^{\circ} \mathrm{C}\right)$, the primary $\alpha$ phase together with Widmanstätten is transformed into the $\beta$ phase. When the temperature drops to approximately $1203 \mathrm{~K}\left(930{ }^{\circ} \mathrm{C}\right)$, globular $\mathrm{K}_{\mathrm{II}}$ phases start to nucleate, usually represented by $\mathrm{Fe}_{3} \mathrm{Al}$. At approximately $1133 \mathrm{~K}\left(860{ }^{\circ} \mathrm{C}\right)$, fine $\mathrm{K}_{\mathrm{IV}}$ precipitates start to exist and take shape, which is also basically $\mathrm{Fe}_{3} \mathrm{Al}$. At approximately $1073 \mathrm{~K}$ $\left(800{ }^{\circ} \mathrm{C}\right)$, the retaining $\beta$ decomposes by eutectoid reactions resulting in the growth of nickel-rich $K_{I I I}$ phase that has a lamellar morphology. ${ }^{[9]}$

The cooling rates for large NAB castings can be very slow, and further complications arise as there are significant variations in the cooling rate at different points in the casting due to variations of thickness. The cooling rates are around $10^{-3} \mathrm{KS}^{-1}$ for a thicker section but for a thinner section, the cooling rate is much higher. ${ }^{[10]}$ The slow cooling rate contributes to the bigger grain size and subsequently reduction of physical and mechanical properties. ${ }^{[6]}$

At room temperature, cast NAB alloy is mainly comprised many phases such as coarse Widmanstätten $\alpha$ phase, particles of $\mathrm{K}$ phases, and islands of martensite $\beta$ phase. Low cooling rates will produce larger grain sizes, microsegregation of the alloying elements, increased size of $\mathrm{K}$ precipitates, and more microdefects. ${ }^{[11]}$

Friction stir processing can be used to refine the grain size and microstructure near the surface of the cast $\mathrm{NAB}$, resulting in a separation and decomposition of coarse Widmanstätten $\alpha$ phase as well as $\mathrm{K}$ phases. ${ }^{[12]}$ FSP reduces or removes casting porosities and produces a more uniform distribution of phases. FSP also dissolves $\alpha, \mathrm{K}_{\mathrm{I}}, \mathrm{K}_{\mathrm{II}}, \mathrm{K}_{\mathrm{III}}$, and $\mathrm{K}_{\mathrm{IV}}$ phases into the $\beta$ phase, and likewise the severe deformation and heating during FSP also result in recovery and recrystallization in the deformed $\alpha$ matrix as well as spheroidization of retaining lamellar $\mathrm{K}_{\mathrm{III}}{ }^{[13]}$. Equiaxed $\alpha$ grain dominates the microstructure of FSP NAB. The newly equally sized grain exhibits a compact microstructure with no porosity and produces a more corrosion-resistant surface for the NAB component.

\section{B. Cavitation Erosion in $N A B$}

As a ship propeller rotates, zones of low pressure at various points in the blade surface create bubbles due to the reduced boiling point of water at that low pressure. The bubbles can rapidly and violently collapse when the low pressure conditions cease to exist as the blade moves through the water. The imploding bubbles produce a high velocity jet of liquid that impinges energetically onto the solid surface of the blades. The repetitive jet impingements will create a localised cavitation failure on the surface and subsequent mass removal from the blade surface. The resulting cavitation pits create increased turbulence and act as nucleation sites for further cavitation bubbles.

The effect described above is known as cavitation erosion. In time, the damage on the surface can be catastrophic as the blade can be totally separated from the main body of the propeller. So, it is primarily important that the specific area where the cavitation actively takes place should be modified so that resistance to cavitation damage is maximised, and the service life of the component is prolonged.

FSP has the ability to modify the surface microstructure and improve the mechanical properties. ${ }^{[6]}$ It enables the newly formed surface to exhibit a finer grained microstructure with higher hardness, thereby increasing resistance to cavitation damage. FSP also produces surface material that, when appropriately finished, has less small-scale defects such as porosity, scars, pits, and so on that act as nucleation sites for cavitation. ${ }^{[6]}$

For the specific case of cavitation erosion of NAB, a number of studies ${ }^{[1,14,15]}$ have quantified the erosion performance of cast material. Other articles have studied both mechanical effects as well as the electrochemical factors involved. ${ }^{[16,17]}$

\section{Electrochemical and Crevice Corrosion}

The corrosion behavior of cast NAB in seawater has been well documented. ${ }^{[18-20]}$ Kear et al. ${ }^{[19]}$ have reviewed the corrosion of copper in chloride media, indicating that the corrosion process is complicated by the formation of a surface film or oxide layer. In comparison with 
copper, it can be determined that the electrode process of NAB is also anodic dissolution of copper, and it may form cuprous dichloride anion simplified as Eq. [1] and the oxygen reduction as cathodic process Eq. [2]:

$$
\begin{gathered}
\mathrm{Cu}+2 \mathrm{Cl}-e \rightarrow \mathrm{CuCl}_{2}^{-} \\
\mathrm{O}_{2}+2 \mathrm{H}_{2} \mathrm{O}+4 e \rightarrow 4 \mathrm{OH}^{-} .
\end{gathered}
$$

Basically, cuprous oxide $\left(\mathrm{Cu}_{2} \mathrm{O}\right)$ is formed by a dissolution process ${ }^{[13]}$ as follows:

$$
2 \mathrm{CuCl}_{2}^{-}+2 \mathrm{OH}^{-} \rightarrow \mathrm{Cu}_{2} \mathrm{O}+\mathrm{H}_{2} \mathrm{O}+4 \mathrm{Cl}^{-} .
$$

The presence of aluminum increases the corrosion resistance of copper in seawater and also promotes the formation of an oxide layer. The layer is then realised by the complexion of $\mathrm{Al}$ by the chloride and followed by hydrolysis to produce an aluminum hydroxide layer ${ }^{[13]}$ :

$$
\begin{gathered}
\mathrm{Al}+4 \mathrm{Cl}^{-} \rightarrow \mathrm{Al} \mathrm{Cl}_{4}^{-}+3 e^{-} \\
\mathrm{AlCl}_{4}^{-}+3 \mathrm{H}_{2} \mathrm{O} \rightarrow \mathrm{Al}(\mathrm{OH})_{3}+3 \mathrm{H}^{+} 4 \mathrm{Cl}^{-} .
\end{gathered}
$$

Schussler et al. ${ }^{[21]}$ report that the proactive oxide layer comprises $\mathrm{Al}$ and $\mathrm{Cu}$ oxides $\left(\mathrm{Cu}_{2} \mathrm{O}\right.$ and $\left.\mathrm{Al}_{2} \mathrm{O}_{3}\right)$, which contributes to the good corrosion resistance of the NAB samples. The oxide layer consists of $\mathrm{Cu}$ in the outer region, and $\mathrm{Al}$ is rich in the region opposite to the base metal. The oxide layer acts as a barricade and hinders the ions movement across the corrosion product, especially the sustainable proactive layer that forms quickly on the NAB surface.

An analysis done by Wharton et al. ${ }^{[22]}$ describes the corrosion characteristics of cast, wrought, and heattreated NAB alloys in seawater. Wrought NAB contains very little $\beta$ and $\mathrm{K}_{\text {III }}$ phases. Applying sufficiently high temperatures during heat treatment minimises the corrodible $\beta$ phase and increases the density of the fine $\mathrm{K}$ phase precipitates in the phase region. The report describes how the corrosion rate is influenced by metallurgical composition, processing history, and surface roughness.

In another report, Wharton et al. ${ }^{[13]}$ claim that NAB experiences crevice corrosion which, as the name implies, occurs in confined areas where fluid can access but cannot readily flow. For NAB, crevice corrosion starts occurring near the eutectoid regions with only a small attack of the $\mathrm{Cu}$-rich $\alpha$ phase within the region of $\alpha+K_{\text {III }}$ eutectoid. Due to the nature of $K_{\text {III }}$ phase, it was possible for crevice corrosion to reach a depth of $80 \mu \mathrm{m}$ in 30 days of testing. The $\alpha$ grains showed minimal attack, due to the presence of a large portion of $\mathrm{K}_{\text {III }}$ phase near the eutectoid region.

\section{EXPERIMENTAL PROCEDURE}

\section{A. Material Specification}

The chemical composition of NAB as required by the Australia Defence Standards for marine applications is shown in Table I.

\section{B. Friction Stir Processing Procedure}

As the focus of this study is to test the feasibility of using FSP with low plunge force to improve the surface properties, the penetration depth and the amount of the heat generated were irrelevant. The experiment was conducted on an industrial robot (ABB IRB 6660) using a cast test plate sized $100 \times 100 \times 40 \mathrm{~mm}$ which was processed with alloy-based tipless FSP tool designed for Titanium and Nickel alloys. The diameter of the shank was $20 \mathrm{~mm}$, and the length was $20 \mathrm{~mm}$ as well. The contact surface was $9 \mathrm{~mm}$ diameter. The tool was obtained from CFSWT China which is ISO9001: 2008 certified. A rotational speed was $4000 \mathrm{rpm}$, and a plunge force was $1750 \mathrm{~N}$ (70 pct of the robot's force capability). The transverse speed was $0.5 \mathrm{~mm} / \mathrm{s}$, and the tilting angle was $1 \mathrm{deg}$. The length of each run was $30 \mathrm{~mm}$, and multiple overlapping runs were made, as can be seen in Figure 1. As the tool reaches the full penetration at the surface, the temperature at the surface contact could be reached near solidus temperature estimated at least $1273 \mathrm{~K}\left(1000{ }^{\circ} \mathrm{C}\right) .{ }^{[23]}$

\section{Sample Preparation and Hardness Testing Procedure}

The friction-stir processed area was CNC wire cut from the test plate. A number of 5-mm-thick samples were then produced using an Accustom 50 precision cutting machine to the required sizes for various tests. The samples were mounted using a Struers Citopress20 hot mounting. DuroFast resin was used to preserve the edges of the NAB specimen. The mounted samples were ground and polished using a modular Struers Tegra system consisting of a TegraPol-21 grinding and polishing table, a TegraForce-5 specimen mover, and a TegraDoser-5 automatic dosing system. The samples were etched using a solution of $5 \mathrm{~g} \mathrm{FeCl}_{3}+2 \mathrm{ml} \mathrm{HCl}+$ $95 \mathrm{ml} \mathrm{C}_{2} \mathrm{H}_{5} \mathrm{O}$.

A LECO M400-H1 microhardness tester with a Vickers indenter was used for microhardness measurements. A test load of 200 gf was used, and a number of locations were selected to determine the overall surface hardness. Hardness testing was performed at three different layers (or surface depths) of the processed sample, with each layer containing a minimum of nine spots. The layers were the SZ, the ThermoMechanical Affected Zone (TMAZ 1), and the TMAZ 2 bottom section from the FSP surface. There was also a layer from the unprocessed cast NAB in the HeatAffected Zone (HAZ) of the test plate. The layers were divided with approximate distance of $200 \mu \mathrm{m}$, and the indentation spots were taken along the surface region in the marked border. The illustration is shown in Figure 4. The microstructure was examined using an optical microscope and Leica Application Suite software with the magnification ranging from 4 to $100 \mu \mathrm{m}$.

\section{Cavitation Erosion Testing}

As NAB is widely used in marine environments, seawater taken from the Tasman Sea was used for both cavitation and corrosion testing, to simulate the pro- 
Table I. The Composition of Cast NAB According to DSTAN 2000

\begin{tabular}{llccccc}
\hline Element & Aluminum & Iron & Nickel & Manganese & Copper & Impurities \\
\hline Weight percentage (wt pct) & 8.8 to 9.5 & 4.0 to 5.0 & 4.5 to 5.5 & 0.75 to 1.3 & remainder & $<0.25$ \\
\hline
\end{tabular}

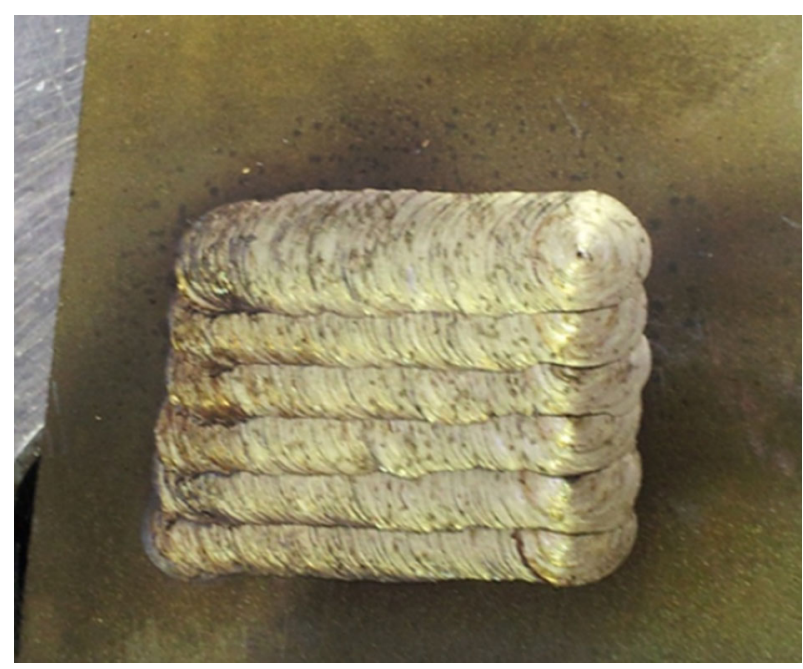

Fig. 1-FSP NAB surface after the process.

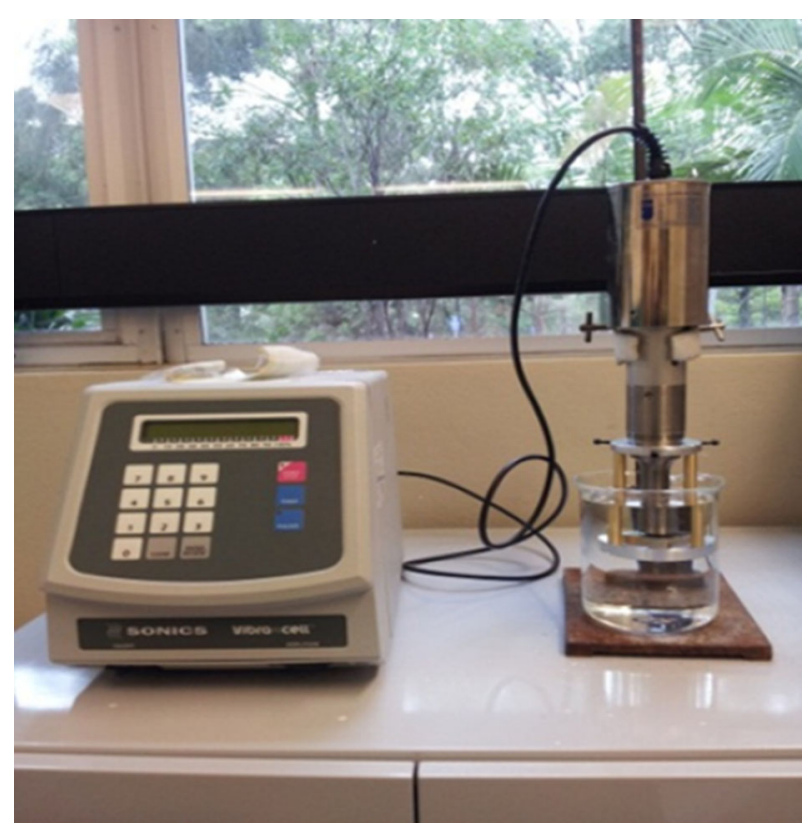

Fig. 2-Cavitation erosion testing apparatus.

spective operating environment. The particular test fluid was filtered, and the $\mathrm{pH}$ level was measured at 8.0 (Figure 2).

The cavitation tests were adapted from ASTM G32$92^{[24]}$ for cavitation erosion using vibratory analysis. An ultrasonic processor (Sonic Vibra Cell VC505, 500 Watt) was used to produce the vibratory wave at a frequency of $20 \mathrm{kHz}$ and amplitude of $25 \mu \mathrm{m}$. The sample and probe were located in the test fluid using the fixture shown in Figure 3, held at a separation distance of $2.0 \mathrm{~mm}$ using a feeler gauge to maintain consistency between the samples. The sample size used was $30 \mathrm{~mm} \times 30 \mathrm{~mm} \times 13 \mathrm{~mm}$, and the probe diameter was $19 \mathrm{~mm}$. Particular care was taken when immersing the fixture in the liquid to ensure that the probe was fully immersed with the sample to the required depth. A copper cooling coil (not shown in Figure 3) was placed at the bottom of the $600 \mathrm{ml}$ beaker to maintain a temperature of $25^{\circ} \mathrm{C} \pm 1{ }^{\circ} \mathrm{C}$ by controlling the circulation of chilled water.

The samples were tested for 12 hour. For every 2 hour, the sample weight was recorded and photos of the erosion surface taken. This procedure was used to establish the weight loss as a function of time. An analytical balance with the accuracy of \pm 0.0001 grams was used to measure the sample weight. The test fluid was replaced after 9 hour into the test cycle, and replaced for the commencement of testing for each sample.

\section{E. Corrosion Testing}

The test surface of each NAB corrosion sample was polished with 600 grit paper using a LECO GP-20 polisher. The samples were then wrapped with a waterproof tape with a 6-mm-diameter aperture located at the center of the sample, as shown in Figure 3. The auxiliary or counter electrode was a porous graphite rod, and a saturated calomel electrode (SCE) was connected as the reference electrode. A CH Instruments (electrochemical analyser 600E) and associated software package were used to control the experimental process. The experiments were performed at a room temperature of $23^{\circ} \mathrm{C} \pm 2{ }^{\circ} \mathrm{C}$. Both samples were tested using filtered seawater as the test solution.

The equipment uses the potentiodynamic method of polarization. The testing cell uses a three-electrode configuration where there is a flow of current between the working and the auxiliary/counter electrode. This current was measured with a zero-resistance ammeter circuit, and the potential of the coupled electrode, with respect to the reference electrode, was also measured with high input impedance circuitry.

To produce the polarization graph, the potentiodynamic voltage was swept between -1.0 and $+1.0 \mathrm{~V}$ with a scan rate of $0.002 \mathrm{Vs}^{-1}$. The current densities were determined from the polarization curves using the Tafel extrapolation method, implemented by software.

\section{RESULTS AND DISCUSSION}

\section{A. Hardness Testing}

Hardness measurements were conducted on layers of the friction-stir processed NAB. The location of these 


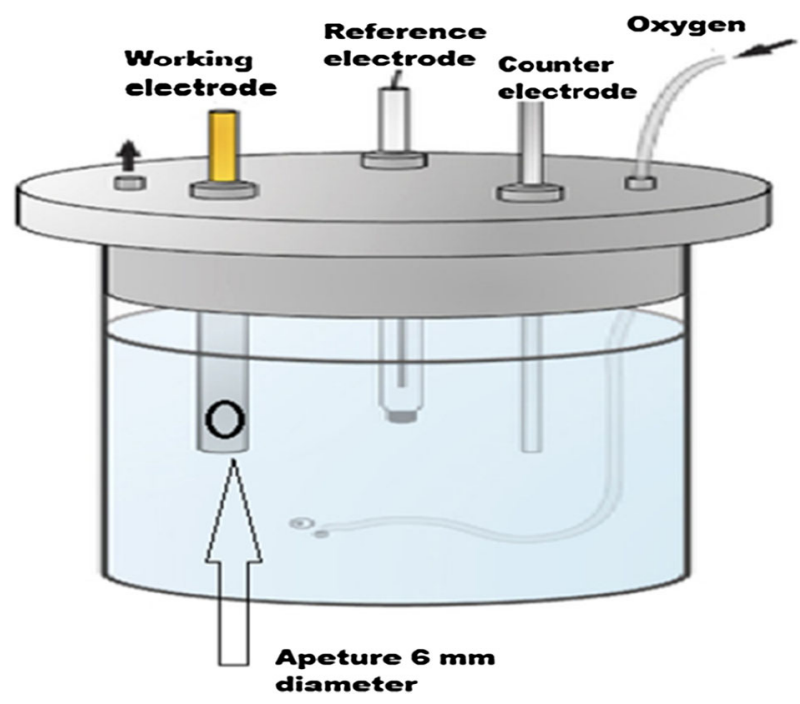

Fig. 3-Corrosion testing cell schematic.

layers is illustrated in Figure 4(a), and the indentations of the Vickers Hardness are illustrated in Figure 4(b). A further set of hardness measurements were performed at the surface of the original as-cast NAB test plate. The results obtained were plotted in Figure 5.

The average hardness of the FSP SZ measurement is $304 \mathrm{HV}_{0.2}$, the TMAZ 1 average is $265 \mathrm{HV}_{0.2}$, and the TMAZ 2 average is $237 \mathrm{HV}_{0.2}$. All of these are significantly higher than the hardness exhibited by the original as-cast $\mathrm{NAB}$ of $187 \mathrm{HV}_{0.2}$. The uppermost layer of the FSP SZ exhibits a hardness increase of 62 pct over the unprocessed material; so this is expected to translate into a significant improvement in resistance to cavitation erosion.

\section{B. Microstructural Analysis}

The microstructure of the original cast NAB alloy is shown in Figure 6(a). The figures show various types of phases present in this type of alloy. Usually, the microstructure contains columnar grains of $\alpha$ phase in copper-rich solid solutions. Also, present are some small volumes of lamellar eutectoid phases of $\beta$ phase which are martensitic and intermetallic. $\mathrm{K}$ phases are basically $\mathrm{K}_{\mathrm{I}}, \mathrm{K}_{\mathrm{II}}, \mathrm{K}_{\mathrm{III}}$, and $\mathrm{K}_{\mathrm{IV} \cdot{ }^{[11]}}$

The $\mathrm{K}_{\mathrm{I}}$ phases are the large dendritic shape similar to rosette shape precipitate. The $\mathrm{K}_{\text {II }}$ phase is also similar to dendritic shape, albeit a little bit smaller than the $\mathrm{K}_{\mathrm{I}}$.

The $\mathrm{K}_{\text {III }}$ precipitates are globular eutectoidal decomposition products of lamellar pattern. The $\mathrm{K}_{\mathrm{IV}}$ precipitates are in the shape of fine particles of different sizes and spreading throughout the grains along certain crystallographic directions. The $\mathrm{K}_{\mathrm{I}}, \mathrm{K}_{\mathrm{II}}, \mathrm{K}_{\mathrm{III}}$, and $\mathrm{K}_{\mathrm{IV}}$ phases are all iron-rich precipitates, and they form a foundation of the $\mathrm{Ni} \mathrm{Al}$ alloys. The $\mathrm{K}_{\mathrm{II}}$ and $\mathrm{K}_{\mathrm{IV}}$ precipitates are found and estimated to be $10 \mu \mathrm{m}$ in size. Also, present is a precipitate-free zone, which can be observed at the border of the grains.

Figures 6(a), (b), and (c) show the microstructures of the friction-stir processed NAB for layers of cast NAB, SZ, and TMAZ, respectively. From these figures, it can

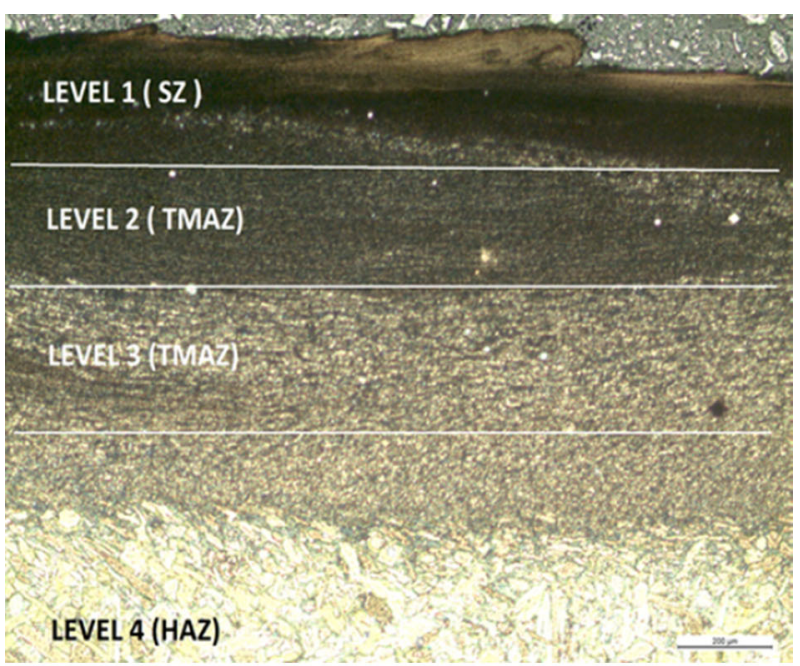

(a)

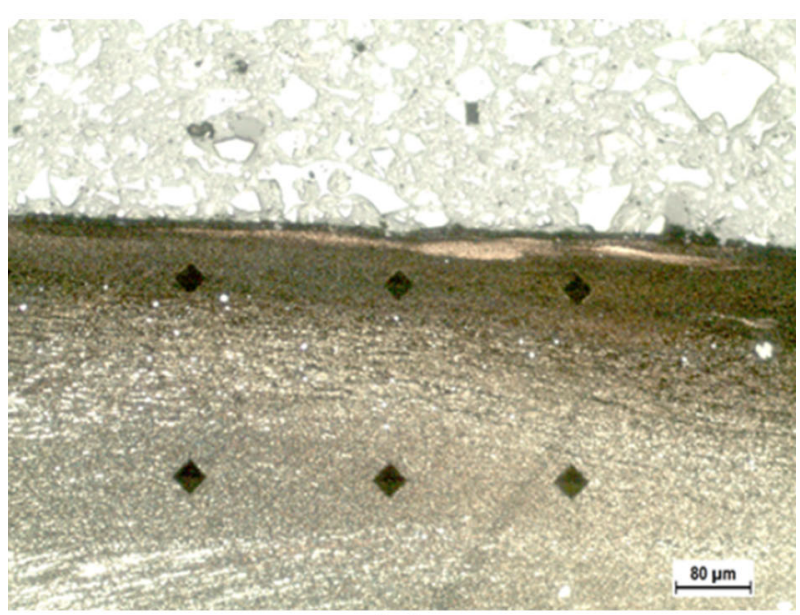

(b)

Fig. 4 - (a) Locations of the hardness test layers, $(b)$ Illustrations of Vickers Hardness points.

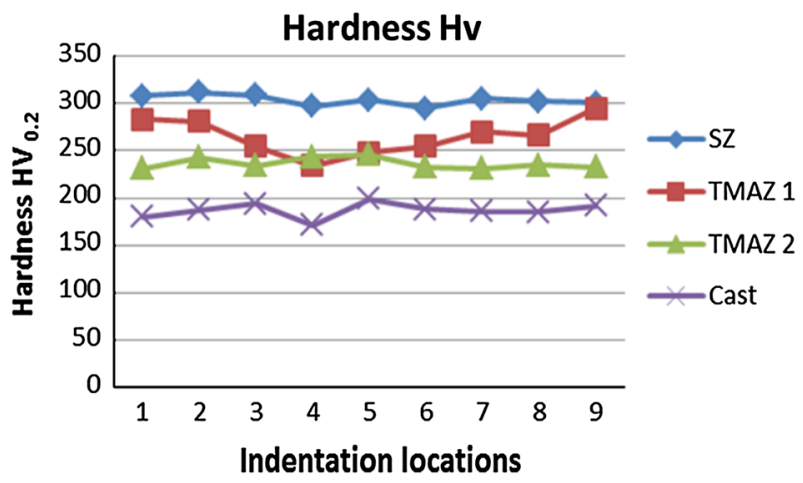

Fig. 5-Vickers MicroHardness distribution results.

be seen that the FSP NAB succeed to refine the grain structure and eliminates porosity defect and homogenised the microstructure, and therefore increase the hardness, tensile properties, and fatigue strength. ${ }^{[25]}$ The effects of FSP and high cooling rates at the processed 


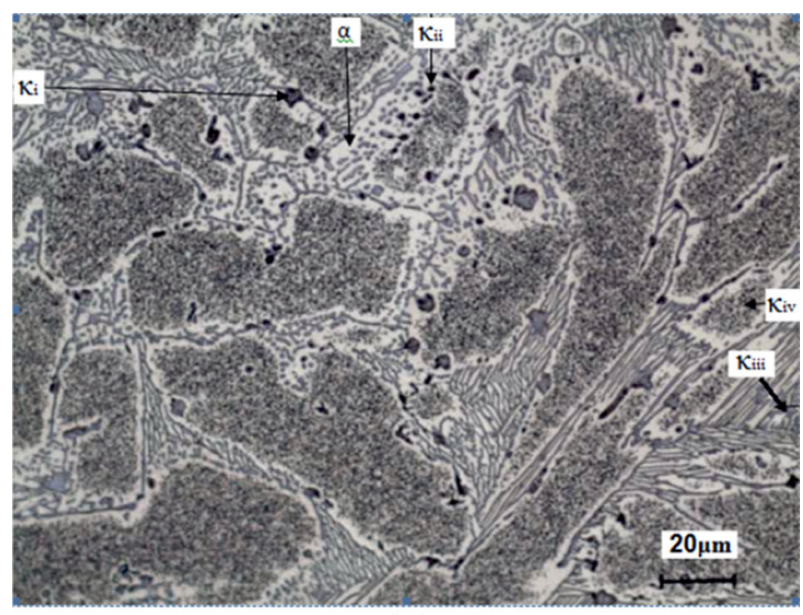

(a)

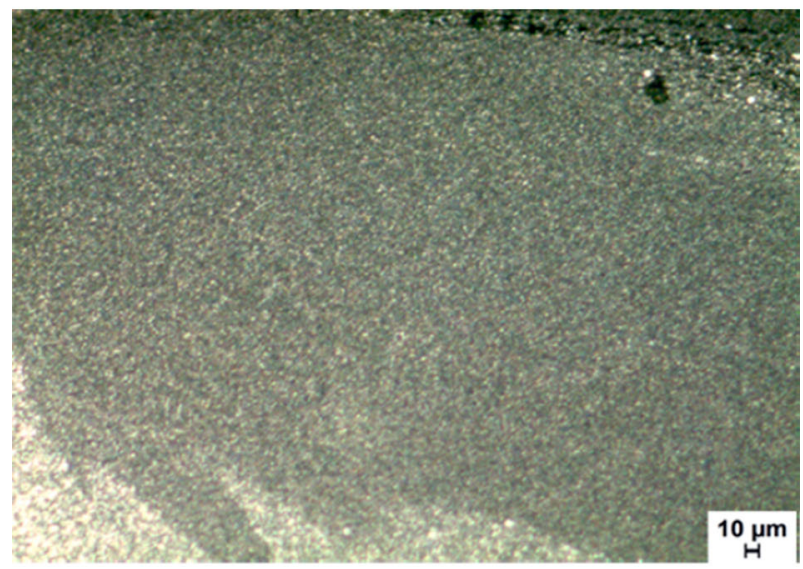

(b)

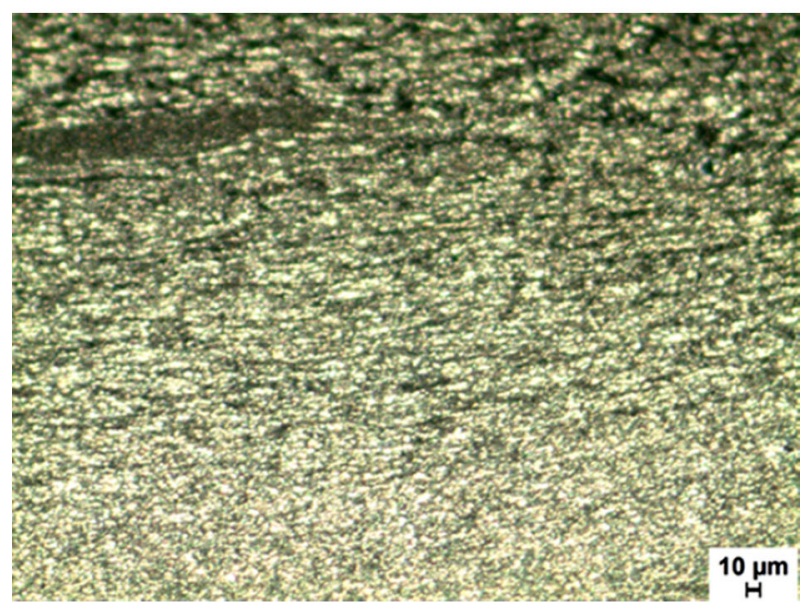

(c)

Fig. 6-(a) Microstructure of cast NAB, (b) the microstructure of FSP NAB in the stir zone (SZ) area, $(c)$ thermo-Mechanical Affected Zone (TMAZ).

surface create highly packed grain structures that alter the mechanical properties. Wang et al. ${ }^{[26]}$ state that higher grain boundary densities lead to the formations of a stable and proactive passive film. This closedpacked structure binds the fine grain and produces improved surface mechanical properties.
The first layer or the SZ of the surface is the most critical, and it is hardened due to the abrasion between the FSP tool and the NAB surface. The area is mostly affected by the heat of the abrasion process and is plastically deformed during processing. As it cools rapidly, the grain boundary does not have ample time to normalise, instead recrystallising with a much smaller grain size due to the sudden drop of temperature. The estimated average grain size of this processed top layer is 1 to $5 \mu \mathrm{m}$, a very significant reduction in comparison to an average grain size of 100 to $150 \mu \mathrm{m}$ for the cast material shown in Figure 6(a). These results are similar to those reported by others ${ }^{[25]}$ who have applied FSP to $\mathrm{NAB}$ using conventional machines rather than robotic manipulators.

\section{Cavitation Erosion Testing}

The weight losses incurred by the processed and cast NAB samples during the 12 hour cavitation erosion tests are shown in Figure 7. These results immediately demonstrate a marked improvement in erosion resistance of the FSP material.

No weight loss was detectable in the first hour, due to the presence of an intact surface oxide layer on both samples, consisting mainly of $\mathrm{Cu}_{2} \mathrm{O}$ and $\mathrm{Al}_{2} \mathrm{O}_{3} \mathrm{~s},{ }^{[12]}$ which resists the formation of pits or cavities. Differences in erosion rates became evident after the first hour as microscopic surface damage reached a certain point that allowed for an approximately constant rate of weight loss to occur thereafter.

This progression has been discussed in earlier studies by Preece, ${ }^{[27]}$ which describe cavitation mass loss occurring in distinct stages. The first stage is an incubation period where no mass loss is seen. As stated before, during this stage, the vibratory waves break down the oxide layer and intermetallic bonds between the grains. The second stage is called the accumulation period where the mass loss is significant and consistent. At this point, most of the surface bonds have been weakened and broken. There is a lack of oxide layer resistance. The surface is more easily eroded as there are few high strength metallic bonds holding the grains. A consistent amount of mass loss can be observed during this stage in Figure 7 for both cast and FSP samples.

After 5 hours, the effects of cavitation erosion became evident directly below the ultrasonic probe for both cast NAB and FSP NAB samples. The samples showed signs of slight surface roughening and pale coloring.

After 9 hours, the presence of large surface cavities became obvious for both samples, with a dark-colored marking on the surface under the probes of both the cast and FSP sample. By this stage, the cavities were penetrated deeply into the surface microstructure.

After 12 hours of cavitation erosion testing, the difference in mass loss between cast and FSP NAB samples became significant. The cast NAB exhibited a very rough surface with the presence of large cavities due to ductile tearing that produced a pale color. The FSP sample exhibited less visual evidence of cavitation and ductile tearing, and the overall surface color was not as pale as the cast sample. 
Comparison between FSP and Cast Nab Weight loss vs Time

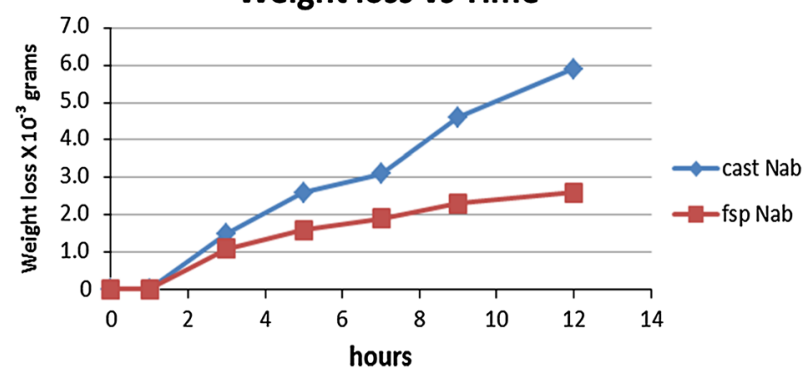

Fig. 7-Weight loss for cast NAB and FSP NAB.

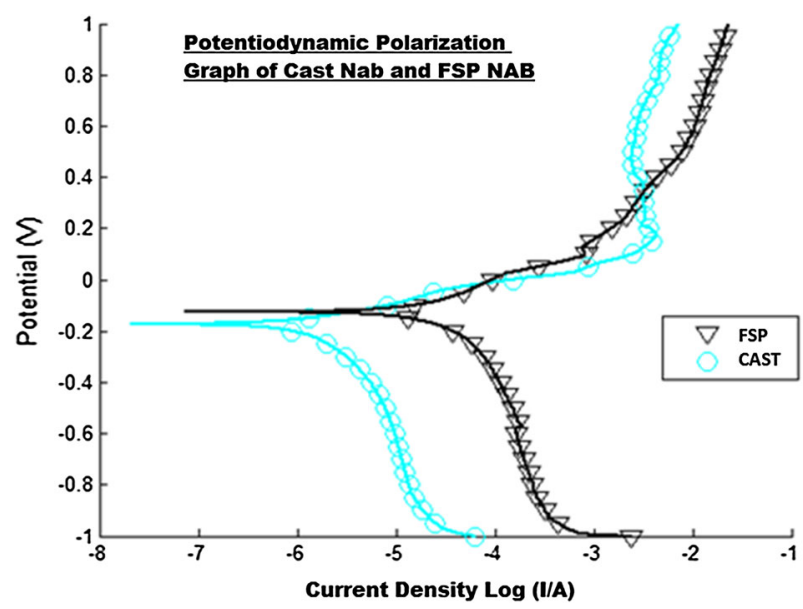

Fig. 8-Polarization curve for cast NAB and FSP NAB.

Using the data in Figure 7, the average mass loss rate for cast NAB is 492 micrograms/hour, while for the FSP sample, the mass loss rate is 217 micrograms/hour, under the conditions of this test. This represents a $56 \mathrm{pct}$ reduction in mass loss due to the robotically applied FSP surface

The improved resistance to cavitation erosion can be attributed to the grain size reduction (of two orders of magnitude) described in the previous section, and the corresponding increase in hardness. Both factors resist the mechanisms through which cavitation produces surface damage and erosion.

\section{Corrosion Testing}

The electrochemical polarization graphs of cast NAB and FSP NAB, as tested in filtered seawater, are shown in Figure 8. Both the cast and FSP samples show typical Tafel behavior.

The range of applied potential difference was +1 to $-1 \mathrm{~V}$ with respect to the SCE. The corrosion potential $\mathrm{E}_{\text {corr }}$ (the voltage at which a current minimum occurs) can be clearly determined as there is a sharply defined reduction of corrosion current (over an order of magnitude) at this point. The corrosion potential for cast NAB is $-0.171 \mathrm{~V}$, while for FSP NAB, it is $-0.126 \mathrm{~V}$. The measured current minima were very similar at the corrosion potential.
The increased corrosion resistance of FSP NAB is attributable to the following factors. First, the finer grain structure of FSP NAB contributes slightly to the improvement of corrosion resistance relative to the coarser-grained microstructure of cast NAB. The finer grain closes the possible porosities and corrosive points for the ions to attack the surface. The observations are quite similar to the report by Ferrara et al. ${ }^{[28]}$ who state that the depth of attack is influenced by the size and the distributions of the microconstituents. The coarser microstructure provides deeper corrosion paths for the ions or the corrosive solutions to attack the intergranular structure. FSP NAB reduces the corrosion path depth, and hence greatly reducing the effects of intergranular attack, and in turn increases the corrosion resistance factor.

Imperfections, porosities, scars, and impurities are considered as catalysts for corrosion effect. These imperfections open up the surface to a larger area and make it easier for the corrosive solutions to actively attack the lower surface and the intergranular structure as well. Principally, these imperfections will provide a concentrated catchment area for the ions to initialise the attack. Therefore, the attack will be much stronger and faster, because at this point, the corrosive ions are highly active. The fine closely bound FSP NAB microstructure offers less imperfections as well as fewer catchment areas for the ions to initialise the corrosive attack. Because there is no active area for the corrosions to start, a longer time is needed for the corrosive ions to initiate and penetrate the FSP microstructure. Thus, this factor multiplies the corrosive resistance of FSP NAB greatly.

The $\mathrm{K}$ phases ( $\mathrm{FeAl}, \mathrm{Fe}_{3} \mathrm{Al}$, Nial, and $\mathrm{Ni}_{3} \mathrm{Al}$ ) exhibit an inhomogeneous and coarse microstructure of cast NAB, which automatically promotes corrosion due to more exposed grains, and it is easier for the corrosive liquid to attack. In FSP NAB, the morphology of the K phases has changed, and segregation is improved, and hence increasing the corrosion resistance. Surekha et $a .^{[29]}$ state that the FSP increases the immersion, electrochemical, and salt spray corrosion resistance of AA 2219-T87 alloy in $\mathrm{NaCl}$ solution. The corrosion resistance increases as the number of FSP cycles is increased and also as the FSP tool rotational speed is increased. The effect of $\mathrm{CuAl}_{2}$ dissolution particles has reduced the number of sites available for the galvanic coupling. The immersion and salt spray results of Surekha et al. are similar to the results obtained here.

The results obtained in this study agree with the findings of $\mathrm{Ni}$ et $a l^{[25]}$ who conducted a similar experiment which found that the weight loss of cast $\mathrm{NAB}$ after 50 hour was close to $9 \mathrm{grams} / \mathrm{m}^{2}$, but the weight loss of FSP NAB was just above $5 \mathrm{grams} / \mathrm{m}^{2}$. Ni et al. stated that the FSP sample showed a much lower corrosion rate than the cast sample due to the optimisation of the microstructure, such as the refinement of grain size, elimination of porosities, and alleviation of the $\mathrm{K}$ phase segregation.

\section{E. Conclusions}

The application of low force $(1750 \mathrm{~N})$ robotic friction stir processing (FSP) to the surface of cast NAB has 
proven successful in refining the coarse into a small grained structure while causing $\mathrm{K}$ phase segregation. The resulting improvements in surface material properties and performance were found to be

1. The Vickers hardness of the processed NAB was up to 62 pct higher than that exhibited by the unprocessed cast sample. For the processed material, hardness was measured at 3 levels of the frictionstirred zone. The top level (SZ) averaged $304 \mathrm{HV}_{0.2}$, the second level (TMAZ 1) averaged $281 \mathrm{HV}_{0.2}$, and the lower level (TMAZ 2) averaged $235 \mathrm{HV}_{0.2}$. In comparison, the cast NAB exhibited an average hardness of $187 \mathrm{HV}_{0.2}$.

2. In comparative 12-hour cavitation erosion tests, the cast NAB showed an average weight loss rate of 492 micrograms per hour, while the FSP sample eroded at 217 micrograms per hour, corresponding to a 56-pct reduction.

3. The corrosion potentials of the NAB and FSP NAB samples were measured at -0.171 and $-0.126 \mathrm{~V}$, respectively. The processed material displays less anodic behavior due to the smaller value of the voltage. This should result in lower electrochemical corrosion rates for processed NAB components that are exposed to in-service marine environments.

In view of these results, robotic FSP with its lower force provision is a promising tool for the economical and effective processing of complex surfaces in cast NAB components.

\section{REFERENCES}

1. M.G. Fontana: Corrosion Engineering, 3rd ed., McGraw Hill Education, New Delhi, 2005.

2. E. Culpan and G. Rose: Br. Corros. J., 1979, vol. 14 (3), pp. 160-66.

3. E.A. Culpan and G. Rose: J. Mater. Sci., 1978, vol. 13 (8), pp. $1647-57$.
4. R.C. Barik, J.A. Wharton, R.J.K. Wood, K.S. Tan, and K.R. Stokes: Wear, 2005, vol. 259 (1-6), pp. 230-42.

5. A.L. Pilchak: Ph.D. Thesis, The Ohio State University, Ohio, 2009.

6. K. Oh-ishi, A.P. Zhilyaev, and T.R. McNelley: in Materials Science Forum, Trans Tech Publications, 2006.

7. D.R. Ni, P. Xue, D. Wang, B.L. Xiao, and Z.Y. Ma: Mater. Sci. Eng., A, 2009, vol. 524 (1-2), pp. 119-28.

8. W.R. Longhurst: Ph.D. Thesis, Vanderbilt University, 2009.

9. K. Oh-Ishi and T.R. McNelley: Metall. Mater. Trans. A, 2004, vol. 35A, pp. 2951-61.

10. B.P. Rosemark: M.Sc. Thesis, Department of Mechanical Engineering, Naval Postgraduate School, Monterey, CA, 2006.

11. A. Al-Hashem and W. Riad: Mater. Charact., 2002, vol. 48, pp. 37-41.

12. McNelley, T.R., Swaminathan, S.,Su, J.Menon, S., A Microstructure-Processing Relationships in Friction Stir Processing (FSP) of NiAl Bronze. 2009, DTIC Document.

13. J.A. Wharton and K.R. Stokes: Electrochim. Acta, 2008, vol. 53, pp. 2463-73.

14. A. Al-Hashem: Corrosion, 1995, vol. 51, pp. 331-42.

15. S. Hanke, A. Fisher, and M. Beyer: Wear, 2011, vol. 273, pp. 3237.

16. C.T. Kwok, F.T. Cheng, and H.C. Man: Mater. Sci. Eng., A, 2000, vol. 290 , pp. $145-54$.

17. P.R. Birkin, R. O'Connor, and C. Rapple: J. Chem. Soc., Faraday Trans., 1998, vol. 94, pp. 3365-71.

18. M.M. Atabaki, M.R. Daroonparvar, K. Moktar, and A.V. Takaloo: Mater. Sci. Appl., 2011, vol. 2, p. 1542.

19. G. Kear, B.D. Barker, K. Stokes, and F.C. Walsh: J. Appl. Electrochem., 2004, vol. 34, pp. 1235-40.

20. R.D. Klassen, P.R. Roberge, and C.V. Hyatt: Electrochim. Acta, 2001, vol. 46, pp. 3705-13.

21. A. Schüssler and H.E. Exner: Corros. Sci., 1993, vol. 34, pp. $1793-$ 1802.

22. J.A. Wharton, R.C. Barik, G. Kear, R.J.K. Wood, K.R. Stokes, and F.C. Walsh: Corros. Sci., 2005, vol. 47, pp. 3336-67.

23. M.W. Mahoney and W.H. Bingel: Microstructural Modification and Resultant Properties of Friction Stir Processed Cast NiAl Bronze, 2003.

24. ASTM_G32, Cavitation Erosion Using Vibratory Apparatus1. 2010.

25. D.R. Ni, B.L. Xiao, Z.Y. Ma, Y.X. Qiao, and Y.G. Zheng: Corros. Sci., 2010, vol. 52, pp. 1610-17.

26. L. Wang, Y. Lin, Z. Zeng, W. Liu, Q. Xue, L. Hu, and J. Zhang: Electrochim. Acta, 2007, vol. 52, pp. 4342-50.

27. C. Preece: Erosion, 1979, vol. 16, pp. 249-308

28. R. Ferrara and T. Caton: Mater. Perform., 1982, vol. 21, pp. 30-34.

29. K. Surekha, B.S. Murty, and K.P. Rao: Surf. Coat. Technol., 2008, vol. 202, pp. 4057-68. 